\section{The use of splenectomy to manage platelet transfusion refractoriness due to anti-human leukocyte antibodies in allogeneic stem cell transplantation}

Pierluigi Piccoli, 3

Massimiliano De Bortoli,1 Rita Balter,1

Anna Pegoraro, ${ }^{1}$ Simone Cesaro'1

1Department of Pediatric Hematology

Oncology, 2Pediatric Surgery,

3Transfusional Medicine, Azienda

Ospedaliera Universitaria Integrata, Verona, Italy

\section{Abstract}

In patients undergoing hematopoietic stem cell transplantation (HSCT), refractoriness to platelet transfusion has been associated with graft failure, delayed engraftment, early mortality and decreased overall survival. Therapeutic strategies include plasma exchange, immunoglobulins, rituximab, and splenectomy. We describe here three patients with refractoriness to platelet transfusion due to anti-human leukocyte antibodies who were splenectomized before HSCT (two cases) and after HSCT (one case) due to the lack of efficacy of other therapies. Splenectomy was uneventful. All three patients achieved a full donor engraftment. We suggest that splenectomy is feasible and effective in HSCT patients to reduce the risk of graft failure or delayed engraftment.

\section{Introduction}

Immune-mediated refractoriness to platelet transfusions is observed in patients who receive non-leukodepleted hemocomponents and develop anti-HLA antibodies.1,2 This complication may have a negative impact on the success of a hematopoietic stem cell transplant (HSCT) because it has been related to graft failure. ${ }^{3-7}$ Moreover, the presence of anti-HLA antibodies has been associated with a delay in the time of neutrophil and platelet engraftment, early mortality and decreased long-term overall survival. ${ }^{5}$ The presence of a spleen and the number of anti-HLA antibodies were the factors that predict the yield of platelet transfusion in HSCT patients. ${ }^{8}$

Therapeutic strategies for platelet transfusion refractoriness include removing the existing antibodies by plasma exchange, inhibiting antibody activity by immunoglobulin, and blocking B cells or plasma cells by rituximab. ${ }^{9}$ Splenectomy can improve the yield of platelet transfusion although it does not alter the number and type of anti-HLA antibodies. ${ }^{8}$

We describe three patients who developed refractoriness to platelet transfusion due to anti-HLA antibodies before HSCT who were successfully managed by splenectomy. Table 1 shows the main demographic and clinical characteristics of the three patients.

\section{Case Report \#1}

K.L. is a 3-year-old female from Georgia diagnosed with myelodysplastic syndrome who was treated mainly with supportive prophylactic nonleukodepleted platelet and red cell transfusions for 19 months until she was referred to our center for an allogeneic HSCT. At admission, she presented with refractoriness to platelet transfusion. The search of anti-HLA antibodies showed the presence of anti-HLA class I (ELISA PakAuto and Quick Screen; GTI Diagnostics, Brookfield, WI, USA). The patient was treated initially with two courses of intravenous immunoglobulins $(0.8 \mathrm{~g} / \mathrm{kg})$ followed by four courses of dexamethasone $(4 \times 40 \mathrm{mg} /$ day $)$ and rituximab $(4 \times 375$ $\left.\mathrm{mg} / \mathrm{m}^{2}\right) .{ }^{10}$ These therapies did not result in significant increment of post-transfusion platelet count so, after three months, a laparoscopic splenectomy was decided upon, preceded by vaccination for capsulated bacteria (one dose of 23valent pneumococcal polysaccharide vaccine, one dose of 4-valent polysaccharide meningococcal vaccine and one dose of hemophilus $B$ conjugate vaccine). Splenectomy was uneventful and the patient was discharged after 8 days. The platelet count increased from $12 \times 109 / \mathrm{L}$ presurgery to $51 \times 10^{9} / \mathrm{L}$ two days after splenectomy. The median transfusion-dependency dropped from three transfusions/week before surgery to none after splenectomy. Five months after splenectomy, the patient underwent an unmanipulated haploidentical stem cell transplant. A stable neutrophil count $>0.5 \times 10^{9} / \mathrm{L}$ and a platelet count $>50 \times 109 / \mathrm{L}$ were achieved after 16 and 42 days from transplant, respectively. The patient was discharged on day +19 post-HSCT. After 11 months from HSCT the patient is well (Lansky play score 100\%), in amoxicillin prophylaxis and in complete hematological remission with blood count always within the normal range and full donor chimerism. The maximum count of platelet reached after splenectomy was $342 \times 109 / \mathrm{L}$

\section{Case Report \#2}

T.Z. is an 8-year-old male from Georgia diagnosed with myelodysplastic syndrome and
Correspondence: Simone Cesaro, Pediatric Hematology Oncology, Piazzale L.A. Scuro 10, Policlinico G.B. Rossi, 37134 Verona, Italy.

Tel..+39.045.812.4931 - Fax: +39.045.812.4909.

E-mail: simone.cesaro@ospedaleuniverona.it

Key words: anti-HLA; splenectomy; alloimmunized patients; transfusion refractoriness; allogeneic stem cell transplantation.

Contributions: SC and MM wrote the manuscript, MM and AP collected the data, FC performed splenectomies, PP performed the tests for antiHLA antibodies; SC, MDB, RB took care of the patients. All authors approved the manuscript.

Conflict of interest: the authors declare no poten tial conflict of interest.

Received for publication: 24 August 2015.

Revision received: 19 December 2015.

Accepted for publication: 29 December 2015

This work is licensed under a Creative Commons Attribution NonCommercial 4.0 License (CC BYNC 4.0).

(C) Copyright M. Mauro et al., 2016

Licensee PAGEPress, Italy

Pediatric Reports 2016; 8:6159

doi:10.4081/pr.2016.6159

treated supportively for 8 months with nonleukodepleted platelet and red cell transfusions until he was referred to our center for allogeneic HSCT. At admission, the patient had refractoriness to platelet transfusion and the search for anti-HLA class I antibodies was positive (ELISA PakPlus; Gen Probe Diagnostics, San Diego, CA, USA). The patient was treated with three courses of intravenous immunoglobulins $(0.8 \mathrm{~g} / \mathrm{kg})$, followed by four courses of dexamethasone $(4 \times 40 \mathrm{mg} /$ day $)$ and rituximab $\left(4 \times 75 \mathrm{mg} / \mathrm{m}^{2}\right) .10$ After 4 months, due to the persistence of a high dependency to platelet transfusions, the patient underwent a laparoscopic splenectomy preceded by vaccination for capsulated bacteria (one dose of 23 valent pneumococcal polysaccharide vaccine, one dose of 4-valent polysaccharide meningococcal vaccine and one dose of hemophilus $B$ conjugate vaccine). The operation was uneventful and the patient was discharged after 9 days. The platelet count was $4 \times 10 \% / \mathrm{L}$ pre-surgery and increased to $19 \times 109 / \mathrm{L}$ seven days after splenectomy. Before surgery, the median requirement was two-platelet transfusions/week, whereas after splenectomy the patient required no further transfusions. One month after splenectomy, the patient underwent a haploidentical stem cell transplant. Neutrophil and platelet engraftment occurred 14 days and 27 days, respectively and the patient was discharged on day +27 post-HSCT. At the last follow-up, at +18 months after 
HSCT, the patient is well, active (Lansky play score 90\%), in amoxicillin prophylaxis and in complete hematological remission with blood count always within the normal range and full donor chimerism. The maximum count of platelet reached after splenectomy was $491 \times 109 / \mathrm{L}$.

\section{Case Report \#3}

V.B. is a 6-year-old male from Ukraine, diagnosed with Juvenile Myelomonocytic Leukemia (JMML) who was treated with hydroxyurea, four courses of cytarabine, and supportive care including non-leukodepleted transfusions for 8 months until he was referred to our center for an unrelated HSCT. Before HSCT, the patient presented with refractoriness to platelet transfusions that was initially attributed to his underlying disease with splenomegaly $(+4 \mathrm{~cm}$ below left costal margin), but subsequently it was considered the result of allo-immunization because the search for HLA antibodies class I and antiGPIb/IX, GPIa/IIa and GP IIb/IIIa (ELISA Pak 12; GTI Diagnostics, Brookfield, WI, USA) resulted positive. Because the HSCT was already scheduled it was decided to proceed, modifying the conditioning regimen by adding a course of plasma exchange, a course of rituximab $\left(1 \times 375 \mathrm{mg} / \mathrm{m}^{2}\right)$ with high dose intravenous methylprednisolone $\left(500 \mathrm{mg} / \mathrm{m}^{2} /\right.$ week $)$ and splenic irradiation. Neutrophil engraftment occurred at day +22 after transplant whereas platelet engraftment did not occur and the patient remained transfusion-dependent with a median requirement of four transfusions /week. Given the persistence of splenomegaly, on day + 91 post-HSCT, a laparoscopic splenectomy was carried out. The surgery was uneventful and the patient was discharged after three weeks. Thirty-five days after splenectomy, the platelet count was $186 \times 10^{9} / \mathrm{L}$ with a maximum of $428 \times 10^{9} / \mathrm{L}$ two months later. At 10 months post-HSCT, the patient is well (Lansky play score 100\%), in amoxicillin prophylaxis and in complete hematological remission with blood count always within the normal range and full donor chimerism.

\section{Discussion}

Platelet refractoriness may occur through a non-alloimmune or an alloimmune mechanism, the latter being caused by sensitization to foreign Class I HLA and, less frequently, to human platelet polymorphic antigens (HPA). ${ }^{11}$ This complication has been reported in between $7-34 \%$ of patients with hematological or oncological diseases, especially in patients who do not receive leuko-depleted or irradiated hemoproducts.11,12 In a randomized trial, the use of leukodepletion or ultraviolet B irradiation of platelets decreased alloimmunization from $13 \%$ to $3 \%$ and $5 \%$, respectively. 13 All three patients described here came from centers where leukodepletion and/or irradiation of blood products were not routinely performed.

The management of platelet refractoriness is based on the modification of the type of platelet product administered or on the modification of the patient immune response. In the first case, the selection of an HLA-matched donor gives the highest post-transfusion platelet increment but it requires the availability of a large pool of dedicated HLA-typed donors. The process of donor selection is timeconsuming without the certainty of finding a matched donor; this procedure is also not ideal for urgent management of bleeding. Alternatively, a platelet cross-matching test with patient serum can be used to more rapidly identify the best platelet unit available. ${ }^{14}$ In our center, both procedures were not feasible because of an inadequate size of donor pool and the inability to perform HLA screening on every donor, so that the only feasible procedure to improve the platelet transfusion yield was to use platelet units derived from a pool of donors. However, this policy did not result in a significant reduction of transfusion frequency, which remained on a daily or two-daily basis. The modification of immune response by highdose of steroids, immunoglobulins and rituximab was not associated with any improvement of patient transfusion-dependency. Considering that HLA sensitization can be a major obstacle to successful engraftment in HSCT, ${ }^{6}$ and may lengthen the period of transfusion-dependency, increasing the risk of severe bleeding episodes, ${ }^{15}$ we opted for splenectomy. Despite the low number of platelets at surgery, the laparoscopic procedure was well tolerated without any significant bleeding. This allowed the first two patients to undergo myeloablative chemotherapy and to engraft both for neutrophils and platelets with-

Table 1. Main demographic, clinical, and transplant characteristics of three patients.

\begin{tabular}{|c|c|c|c|}
\hline & First case & Second case & Third case \\
\hline Gender & Female & Male & Male \\
\hline Country of origin & Georgia & Georgia & Ukraine \\
\hline Underlying disease & Myelodysplasia & Myelodysplasia & JMML \\
\hline Age at diagnosis, years & 3 & 8 & 6 \\
\hline Type of donor & Haploidentical mother & Haploidentical mother & HLA matched unrelated donor (10/10) \\
\hline Myeloablative conditioning regimen & $\begin{array}{l}\text { BU } 3 \times 3.2 \mathrm{mg} / \mathrm{kg} / \text { day; TT } 1 \times 5 \text { mg/kg/day; } \\
\text { Flu } 3 \times 50 \mathrm{mg} / \mathrm{m}^{2} / \text { day }\end{array}$ & $\begin{array}{l}\text { TBI } 2 \text { Gy; BU 3×3.2 mg/kg/day; } \\
\text { TT 2×5 mg/kg/day; Flu 3×50 mg/m²/day }\end{array}$ & $\begin{array}{l}\text { RT } 2 \text { Gy (on spleen); } \\
\text { BU } 43.8 \text { mg/kg/day; } \\
\text { ATG } 3 \times 3.75 \mathrm{mg} / \mathrm{kg} / \text { day; } \\
\text { Cy } 2 \times 60 \text { mg/kg/day; } \\
\text { Mel } 1 \times 140 \text { mg/m²/day }\end{array}$ \\
\hline GVHD prophylaxis & $\begin{array}{l}\text { Tacrolimus/cyclosporine; } \\
\text { Cy } 2 \times 50 \text { mg/kg/day (day + } 3 \text { and }+4 \text { ); } \\
\text { MMF }\end{array}$ & $\begin{array}{l}\text { Tacrolimus/ cyclosporine; } \\
\text { Cy } 2 \times 50 \text { mg/kg/day (day + } 3 \text { and }+4) \text {; } \\
\text { MMF }\end{array}$ & $\begin{array}{l}\text { Intravenous cyclosporin } 3 \mathrm{mg} \\
\mathrm{kg} / \text { day; MTX } 15 \mathrm{mg} / \mathrm{m}^{2} \text { day }+1 \\
\text { MTX } 10 \mathrm{mg} / \mathrm{m}^{2} \text { day }+3,+6,+11\end{array}$ \\
\hline Number of infused CD34+ cells & $4.68 \times 10^{6} / \mathrm{kg}$ & $5.32 \times 10^{6} / \mathrm{kg}$ & $4.16 \times 10^{6} / \mathrm{kg}$ \\
\hline Neutrophil engraftment $\left(>0.5 \times 10^{9} / \mathrm{L}\right)$ & +16 days & +14 days & +22 days \\
\hline Platelet engraftment $(>50 \times 109 / \mathrm{L})$ & + 42 days & +27 days & + 105 days after splenectomy \\
\hline Blood count at last follow up & $\begin{array}{l}\text { + } 11 \text { months; Hb } 12.9 \mathrm{~g} / \mathrm{dL} ; \\
\text { PLT } 319 \times 109 / \mathrm{L} ; \mathrm{WBC} 11.8 \times 109 / \mathrm{L} \\
\text { (neutrophils } 3.1 \times 10^{9} / \mathrm{L} \text { ) }\end{array}$ & $\begin{array}{l}\text { + } 18 \text { months; Hb } 14.7 \mathrm{~g} / \mathrm{dL} ; \text { PLT } 500 \times 109 / \mathrm{L} \text {; } \\
\text { WBC } 13.2 \times 109 / \mathrm{L} \text { (neutrophils } 4.3 \times 109 / \mathrm{L} \text { ) }\end{array}$ & $\begin{array}{l}\text { + } 10 \text { months; Hb } 14.2 / \mathrm{g} / \mathrm{dL} ; \text { PLT } \\
428 \times 10^{9} / \mathrm{L} ; \mathrm{WBC} 10.6 \times 109 / \mathrm{L} \text { (neutrophils } \\
4 \times 10^{9} / \mathrm{L} \text { ) }\end{array}$ \\
\hline
\end{tabular}

JMML, juvenile myelomonocytic leukemia; TBI, total body irradiation; RT, radiation therapy; BU, busulfan; TT, thiotepa; Mel, melphalan; Flu, fludarabine; ATG, anti-thymocyte globulin; Cy, cyclophosphamide; MTX, metothexate; MMF, mycophenolate mofetil. 
out any significant delay in the first two cases described. Interestingly enough, the third alloimmunized patient did not engraft normally for platelets, despite the modification of the conditioning regimen with the addition of plasmapheresis, dexamethasone, rituximab and splenic radiotherapy, and continued to be platelet transfusion-dependent until splenectomy was performed at three months after transplant. Marktel et al. showed that myeloablative and immunosuppressive conditioning before HSCT was not able to modify the number and specificities of anti-HLA antibodies in eight alloimmunized patients who rejected their graft. 8 On the contrary, in a thalassemic alloimmunized patient who had a secondary graft failure, a splenectomy before the second HSCT did result in higher platelet transfusion increment than the first HSCT $(\mathrm{P}=0.03)$. Splenectomy, though not altering the anti-HLA antibody production, can limit its negative impact on the life of both exogenous and endogenous platelets. This finding is in line with the data reported recently by Palandri $e t$ $a l .16$ who showed that in patients with steroidrefractory immune thrombocytopenia, splenectomy had a response rate of $88.5 \%$ after a median follow-up of 20 years; moreover, the response rate was similar to or even higher than rituximab in patients with non-splenic uptake of platelets.

\section{Conclusions}

In conclusion, in alloimmunized patients, laparoscopic splenectomy is a valuable option before HSCT to prevent graft failure, speed platelet engraftment and reduce transfusional burden after HSCT in patients with anti-HLA antibodies. Further studies and longer followup is needed to assess the impact of this choice on long-term infectious morbidity.

\section{References}

1. Sanz C, Freire C, Alcorta I, et al. Plateletspecific antibodies in HLA-immunized patients receiving chronic platelet support. Transfusion 2001;41:762-5.

2. Van Marwijk Kooy M, Van Prooijen HC, Moes M, et al. Use of leukocyte-depleted platelet concentrates for the prevention of refractoriness and primary HLA alloimmunization: a prospective, randomized trial. Blood 1991;77:201-5.

3. Ciurea SO, Thall PF, Wang X, et al. Donorspecific anti-HLA abs and graft failure in matched unrelated donor hematopoietic stem cell transplantation. Blood 2011;118:5957-64.

4. Cutler C, Kim HT, Sun L, et al. Donor-specific anti-HLA antibodies predict outcome in double umbelical cord blood transplantation. Blood 2011;118:6691-7.

5. Spellman S, Bray R, Rosen-Bronson S, et al. The detection of donor-direct, HLA-specific antibodies in recipients of unrelated hematopoietic cell transplantation is predictive of graft failure. Blood 2010;115:2704-08.

6. Yoshihara S, Maruya E, Taniguchi K, et al. Risk and prevention of graft failure in patients with preexisting donor-specific HLA antibodies undergoing unmanipulated haploidentical SCT. Bone Marrow Transplant 2012;47:508-15.

7. Takanashi M, Atsuta Y, Fujiwara K, et al. The impact of anti-HLA antibodies on unrelated cord blood transplantation. Blood 2010;116:2839-46.

8. Marktel S, Napolitano S, Zino E, et al. Platelet transfusion refractoriness in highly immunized beta thalassemia children undergoing stem cell transplantation. Pediatr Transplant 2010;14:393-401.

9. Zhu H, Luo C, He J, et al. Successful engraftment of third allogenic hematopoietic stem cell transplantation after two graft failures and treatment for anti-HLA antibody in a pediatric acquired aplastica anemia patient. Pediatr Transplant 2014;18:896-8.

10. Zaia F, Baccarani M, Mazza P, et al. Dexamethasone plus rituximab yields higher sustained response rates than dexamethasone monoterapy in adults with primary immune thrombocytopenia. Blood 2010;115:2755-62.

11. Novotny VM. Prevention and management of platelet transfusion refratoriness. Vox San 1999:76;1-13.

12. Hod E, Schwartz J. Platelet transfusion refractoriness. Br J Haematol 2008;142: $348-60$.

13. McFarland J, Menitove J, Kagen L, et al. Leukocyte reduction and ultraviolet B irradiation of platelets to prevent alloimmunization and refractoriness to platelet transfusion. N Engl J Med 1997;337:18619.

14. Pavenski K, Freedman J, Semple JW. HLA alloimmunization against platelet transfusions: pathophysiology, significance, prevention and management. Tissue Antigens 2012;79:237-45.

15. Pena JR, Saidman SL, Girouard TC, et al. Anti-HLA alloantibodies in surgical patients refractory to platelet transfusion. Am J Hematol 2014;89:E133-7.

16. Palandri F, Polverelli N, Catani L, et al. The choice of second-line therapy in steroid-resistant immune thrombocytopenia: role of platelet kinetics in a singlecentre long-term study. Am J Hematol 2014;89:1047-50. 